\title{
Depression and Osteoarthritis: Impact on Disability
}

\section{Ray Marks}

Departments of Health, Physical Education and Gerontological Studies and Services, City University of New York, York College and Health and Behavior Studies, Columbia University, Teachers College, New York, USA

*Corresponding Author: Ray Marks Departments of Health, Physical Education and Gerontological Studies and Services, City University of New York, York College and Health and Behavior Studies, Columbia University, Teachers College, New York, USA; E-mail: rm226@columbia.edu

Rec date: July 25, 2014, Acc date: August 7, 2014, Pub date: August 13, 2014

Copyright: (c) 2014 Marks R. This is an open-access article distributed under the terms of the Creative Commons Attribution License, which permits unrestricted use, distribution, and reproduction in any medium, provided the original author and source are credited.

\begin{abstract}
Osteoarthritis, a highly prevalent progressively disabling chronic health condition associated with aging, is frequently addressed from a physical standpoint, rather than a more holistic standpoint, even though psychological correlates are often prevalent co morbid determinants of this condition. This review briefly summarizes the literature on osteoarthritis and depression published over the last 30 years. From this review, it is concluded that depression is a frequent correlate of osteoarthritis disability, and where present heightens the prevailing disabling painful experience consistently and significantly. Since depression is amenable to treatment, it is recommended more attention to routinely screening for depression among osteoarthritis sufferers, rather than doing this sporadically, is strongly indicated for promoting optimal outcomes among this burgeoning population.
\end{abstract}

Keywords: Aging; Depression; Disability; Osteoarthritis; Pain

\section{Introduction}

Osteoarthritis, a progressively destructive joint disease causing varying degrees of unrelenting pain and excess suffering is highly prevalent among all older populations [1-5]. Primarily affecting the articular cartilage lining of freely moving joints, and commonly attributed to the aging process, this highly debilitating disease can be aggravated by a variety of medical comorbidities and biological factors other than age [6-15]. Depression, a frequently observed condition in the older population as well as among people with chronic and/or chronically painful health conditions is another aggravating factor [12,16-24]. Given that osteoarthritis is largely irreversible and that older people are more likely than younger persons to have this condition, the goal of this editorial was to provide a brief overview of the role of depression in the pathway from osteoarthritis pathology to disability and to make appropriate recommendations for advancing clinical practice in this area [9]. Because of the excess personal and societal burden associated with osteoarthritis in the context of older populations, this review focuses specifically on examining evidence the link between depression and the pain experienced by this group. It also discusses:

- The key features of osteoarthritis and depression.

- Some accepted methods of treating depression.

- A framework for possible treatment approaches for clinicians who treat these clients.

It was felt this review would help to raise awareness concerning the role of depression in the context of osteoarthritis disability, particularly with respect to pain, the most common problem resulting from this condition. The information was also considered relevant to identifying optimal intervention strategies for those numerous individuals suffering from this irreversible health condition. Since the role of depression in mediating or moderating the osteoarthritic disease process is often overlooked clinically, and is often not discussed at all in the context of current clinical practice recommendations, the author's purpose was to stress the importance of more concerted efforts to screen for and treat depression where evidenced among older people suffering from osteoarthritis [25-27].

The information was compiled from an extensive review of the English language literature published over the last twenty years using the keywords: Osteoarthritis and Depression. Categories of interest that emerged are discussed below.

\section{Osteoarthritis}

A considerable volume of research has confirmed that osteoarthritis of one or more joints is a highly prevalent disorder causing appreciable disability in aging adults [1-5,28]. A further volume of research has revealed an increasing need for non-operative and operative interventions to minimize osteoarthritis disability [29-33]. A further body of research has outlined the course of osteoarthritis and treatments to minimize pain while limiting patient risk [34,35]. Existing treatments are not always helpful as far as reducing pain and promoting function, however. Moreover, some forms of pain relieving medications may be contra-indicated for some patients, and others recommended for reducing osteoarthritic pain may foster, rather than retard, articular cartilage disintegration, the main problem associated with this condition $[5,7,8,36]$. Others have discussed the importance of mental well-being, psycho-educational interventions and the importance of pain and depression in the context of this disease $[10,37,38]$.

\section{Depression}

Depression, a serious mood disorder associated with persistent feelings of sadness, loss of interest and pleasure in daily activities may occur independently as a separate health condition, or in reaction to the persistent presence of other illnesses, adverse life events and losses, as well as mobility losses, such as those experienced by the older person with osteoarthritis [10]. However, even though research shows severe forms of depression affect $2-5 \%$ of the United States population, and up to $20 \%$ may suffer from milder forms of the illness, especially 
Page 2 of 7

after 70 years of age, especially if they suffer from medical problems, and/or chronic disabling pain, measures are not commonly put in place to identify depression $[39,40]$.

In addition to personal suffering and disruptions that affect the entire family, depression at any age worsens the outlook for the individual as regards their health and medical challenges [39]. This process, in turn, can exacerbate prevailing depression, as well as the outcomes of co-existing physical illnesses quite negatively $[41,42]$. It can also result in excessively high rates of inflammation, a decreased desire for physical activities, weakness, trouble sleeping, anxiety, social withdrawal, and higher rates of bone resorption, as well as pain, all factors that could all interact to magnify the extent of osteoarthritis disability, including the overuse of existing health services $[43,44]$.

\section{Pain}

Pain is the problem of most concern to people with osteoarthritis and Dziechciaz et al. [45] reports the elderly, who are most susceptible to osteoarthritis experience pain more readily than young people. According to the same authors, pain can mask depression, and depression can intensify the pain experience. Recent research highlighting the contribution of central pain pathways together with the sensitization of peripheral joint receptors and changes of the nociceptive process has suggested that there may be a neuropathic pain component in some individuals with minor joint changes but with high levels of pain refractory to analgesic treatment that should be noted [46]. Centrally oriented medications are recommended here, but the role of depression may be helpful to explore as well.

\section{Depression and Osteoarthritis Pain}

As mentioned above, it is not clear in many cases, why many people with osteoarthritis experience more pain than one would expect based on the extent of their bony pathology or their radiographs [46-48]. Recently however, increased attention has been placed on central rather than peripheral processes as well as bio-behavioural mechanisms to account for the seemingly exaggerated pain experience reported by many osteoarthritis sufferers [49-51]. In this regard, it appears that alone or in combination, one factor that may influence the pain experience adversely in people with osteoarthritis is the presence of depression that may arise as a reactive condition in response to their disabling physical and social wellbeing, or as a prevailing comorbid condition [42]. This idea is supported by the observation that unsurprisingly, when sought; depressive symptoms are often observed among those older adults with osteoarthritis who seek treatment due to pain [16].

For example, Salaffi et al. [48], as well Dekker et al. [49,50] found the patients' pain experience and disability scores were strongly influenced by the presence of depressive symptoms. This linkage of pain, depression, and osteoarthritis disability observed by Salaffi et al. [48], is problematic as it is strongly associated with activity avoidance, a wide array of emergent cognitive issues, such as learned helplessness, job dissatisfaction, and an adverse disease outcome [20]. That is, the bulk of the research on osteoarthritis research reveals a consistent picture of potentially debilitating overlapping symptoms, including a low sense of morale, social isolation, helplessness, further depression, anxiety, sleep disturbances, and disability that can heighten and prolong the osteoarthritic pain experience with few comprehensive treatment options [50] and that fostering a positive, rather than ignoring any negative affect, may help to attenuate the prevailing degree of osteoarthritic pain and disability [51]. In light of the growing prevalence of this disease and the highly resistant nature of chronic non-malignant osteoarthritic pain to intervention, where only about 50 percent of cases may report adequate relief from traditional treatments, unravelling this cycle of deleterious events and examining what specific interventions may prove beneficial to the individual patient with this condition appears paramount $[52,53]$. Unfortunately, even though more than $80 \%$ of this population may be in constant pain and have difficulty in accomplishing everyday tasks, current treatment approaches often fail to provide adequate relief, and clearly do not commonly intervene to break the cycle of suffering [54].

\section{Treating Depression}

Since depression is one of the most important predictors of health practitioner visits [44], and can lead to suicide, as well as considerable physical, and social disability, minimizing, preventing or treating depression is strongly indicated among the older population. As well, given that depression can impact disability to a degree commensurate with heart disease, interventions that can address depression as well as related social problems that exacerbate this are strongly indicated $[55,56]$. Those under stress, as well as those with chronic unrelenting pain and inflammation should be especially targeted depending on need.

Such treatments may include counseling, psychotherapy, medications, cognitive behavioral therapy, exercise, and social support among other approaches. Treating comorbid conditions, while enhancing coping skills may also be beneficial [57]. Moreover, to minimize medical costs, plus higher than necessary rates of symptom expression and pain among older people, appropriate personalized or tailored interventions may be indicated [10].

\section{Need for Interventions to Decrease Depression}

As outlined above, preventing or treating depression is paramount in the context of maximizing the well-being of older adults, especially those with osteoarthritis who may have a four-fold risk of incurring depression than those with no arthritis [10]. As well, functional disability, common in older adults, and associated with a high risk of subsequent decline is likely to impacted adversely by depression, as is pain and life satisfaction [58,59]. Thirdly, patients with hip or knee osteoarthritis who exhibited preoperative depressive symptoms had worse patient reported outcomes 3 and 12 months after surgery and were less satisfied than those with no depressive symptoms and depression may be associated with weight gain, which is a risk factor for more adverse osteoarthritis outcomes [52,60,61].

Other evidence shows that depression predicts yearly worsening of the disease and has the potential to increase the risk of incurring predictable functional declines, sleep problems, decreased treatment expectations and increased difficulty in engaging in treatment [62-65]. As well, those with functional impairments and depression, may exhibit high levels of non-compliant behaviors, activity avoidance strategies, catastrophizing, and passive coping styles, plus a higher prevalence of psychopathology than non-distressed patients $[21,40,66]$.

Additional research shows increasing numbers of studies that indicate depression is not uncommon among cases diagnosed as having disabling osteoarthritis, and that in some cases, these rates are substantial. For example, Aflaki et al. [67] found $65 \%$ of knee osteoarthritis cases and $67 \%$ of hand osteoarthritis cases had Beck depression scores higher than 10. As well, 21 percent of the knee 
osteoarthritis cases and $22.8 \%$ of hand osteoarthritis cases had scores greater than 19 , rates of clinically depression that were higher than those recorded in a previous study by Abdel-Nasser et al. of $10 \%$ for adults with knee osteoarthritis, but comparable to cases with rheumatoid arthritis, thought to be a more severe disease, where $23 \%$ of the sample were found to have clinically confirmed depression [68]. Similarly, in a study by Stebbings et al. [69], participants with osteoarthritis reported greater pain, disability, depression and sleeplessness than those with rheumatoid arthritis (all $\mathrm{p}<0.01$ ). In those with osteoarthritis, the correlates of fatigue, often not associated strongly with osteoarthritis, were older age $(\mathrm{p}=0.02)$, sleep disturbances $(p=0.03)$, depression $(p=0.04)$, disability $(p=0.04)$ and lower C-Reactive Protein ( $\mathrm{p}=0.001$ ). Taken, as a whole, these findings support the idea that depression has a direct effect not only on the interpretation of osteoarthritis pain as identified by Lunghi et al. [70], but also on life quality and surgical outcomes of the osteoarthritis patient $[71,72]$.

Other research of cases with osteoarthritis has shown adults with this condition can exhibit progressive decreases in mental health over time $(p<0.001)$, plus a higher prevalence of comorbid conditions relative to age and gender matched controls [73]. As mentioned previously, they also exhibit greater pain as well as a reduced physical ability if depressed $(p<0.05)$, and this association is particularly common among women with the condition $(\mathrm{p}<0.05)$. In turn, their disability, has been associated with a reduced ability to cope, further depression, and more pain $(\mathrm{p}<0.05)[22]$.

In terms of the influence of surgical outcomes, a related study of 171 cases with osteoarthritis suggested those experiencing psychological distress are less likely to be optimistic about engaging in treatments deemed crucial for minimizing this disability than those who are not distressed $[65,74]$. Yet another found outpatients suffering from hip osteoarthritis tended to reduce their activity participation and exposure to both unpleasant as well as pleasant events, if they perceived heightened emotionally stressful symptoms [72].

Consequently, among a fairly representative sample of studies that have specifically examined the relationship between depression and osteoarthritis, most provide clear support for improved efforts to identify, study and treat this psychosocial factor despite the varied samples studied and differing measures and measurement procedures that have been used to examine the presence of depression in the context of osteoarthritis.

For example, Smith and Zautra who examined 88 cases of women with osteoarthritis using 19 items from the Mental Health Inventory reported depression was related to elevations in current and anticipated pain in the next week [26]. Van Baar et al. [75] too, found that regardless of systemic or mechanical mechanisms that influence osteoarthritic pain and disability, psychosocial factors including depression are likely to predict the impact of osteoarthritis more strongly than the extent of damage apparent in the joints . In addition, although it is not clear whether psychological factors are uniquely predictive of osteoarthritis disability, Summers et al. [76] found that even after controlling for disease severity, psychological variables including depression remained strong predictors of individual differences in functional impairment and pain in persons with knee osteoarthritis.

\section{Conclusion}

Aging adults with osteoarthritis, the most common joint disease, may not only be at heightened risk for depression, but those with depression may be more likely to experience more severe forms of the disease than those who are not depressed [77,78]. The presence of depression, especially if undiagnosed and untreated, which is a major cause of constant pain among older populations, may also help to explain why the pain and suffering experienced by some older individuals with osteoarthritis may seem exaggerated [79]. In addition to current osteoarthritis treatment approaches that focus primarily on the physical and biological domains of the disease, the aforementioned findings strongly imply more needs to be done in the context of the psychological realm in efforts to minimize disability and optimize health outcomes for osteoarthritis sufferers. That is, since depression is found to occur among patients with osteoarthritis at rates comparable to those found in other medical conditions, and may prevail in over one fifth of older adults with this condition, more concerted efforts to identify and intervene upon depression where it exists appears highly desirable as outlined by Possley et al. [23,79].

Consequently, from a clinical point of view, early identification of depression, followed by intervention to reduce this may greatly help to avert any excess morbidity, while fostering the osteoarthritic individual's overall wellbeing, as well as their functional ability and social participation levels. On the other hand, older adults with osteoarthritis and concomitant depression who remain untreated are more likely to require high doses of pain relieving medications, as well as more health services than those with no depression [80]. They may also have fewer social contacts, and excessively high body mass indices compared to those osteoarthritis cases not experiencing depression $[54,56,81]$.

In summary, in addition to affecting one's mood as well as one's response to pain in a negative way, the presence of depression has increases activity fatigue, and the overall osteoarthritic disease burden quite significantly $[54,82]$. This excess disease burden significantly increases pain medication usage as well as health care services utilization and predicts low adherence to recommended treatment regimens $[83,84]$.

In this respect, evidence from the chronic pain literature strongly suggests central nervous system influences of emotions and cognitions including individual behavioral characteristics along with psychosocial factors, and increased sensitivity to pain signals by the brain should not be ignored as potent factors that can mediate or moderate osteoarthritis outcomes in older adults [85-87]. That is, it can be assumed that the perceptions, interpretations, and reactions of the affected individual to their impairment will interact with peripheral pain processes to produce or heighten the painful experience, as well as the extent of prevailing disability, thus heightening the changes of incurring reactive depression, even if there is little or no distinctive prevailing painful source that can be demonstrated objectively $[5,88,89]$.

In turn, it appears that if the experience of perpetual pain provokes underlying tendencies towards depression, it can also accentuate feelings of helplessness, poor coping ability, and sleep disturbances commonly associated with depression [90]. This negative series of feedback responses where depression, anxiety and coping ability are significantly correlated with the osteoarthritic patient's pain and disability levels potentially produces a vicious cycle of excess pain and disability, plus varying degrees of negative affect, regardless of the 
prevailing degree of osteoarthritic damage as outlined in Figure 1 [91-93].

Given that osteoarthritis, the fourth most common cause of loss of function leading to disability among adults in most developed countries is irreversible, and does not respond well to medical intervention, efforts to limit, reduce, or prevent osteoarthritis disability appear essential in efforts to avert undue suffering, and to foster the patient's desire to remain independent [66,94]. Since depression can significantly heighten the adverse physical, social, economic, and psychological consequences of the disease, and can occur both as a co-occurring comorbid condition, as well as a reactive condition, identifying and treating all forms of associated depression may be key to reducing or minimizing the magnitude of the osteoarthritis disability. In turn, early intervention may prevent or moderate the prospective onset of severe depression and its detrimental effect on features of the osteoarthritis disease process, such as pain. That is, given that an increased prevalence of at least moderately severe depression has been observed among a reasonable percentage of cases with osteoarthritis, efforts to detect the presence of comorbid depression, followed by appropriate efforts to improve the mental health status of this group may heighten their ability to be active physically, as well as socially, and to thereby meet their personal life affirming goals, as well as their weight goals more readily [78].

As outlined in Figure 1, attempts to both minimize osteoarthritis disability directly, as well as to prevent or treat concomitant depression are likely to have far reaching beneficial effects. Moreover, dealing with the presence of pain, as well as depression, rather than failing to identify and treat this latter problem, can potentially offset excess functional disability, minimize the extent of perceived pain, reduce fears and heighten confidence to cope with pain, and heighten activity participation, rather than the avoidance thereof, thus reducing excess health care costs $[44,83,93-96]$.

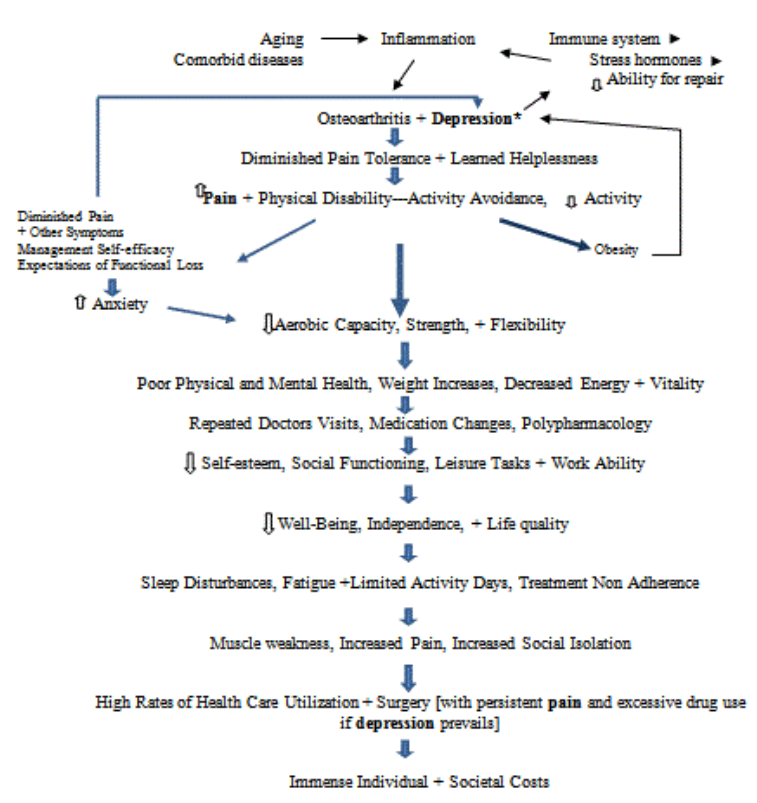

Figure 1: Figure showing, complex set of health related interactions occurring between pain and depression that lead to considerable disability, especially if untreated. ${ }^{*}$ Depression may be reactive or present as a comorbid condition
To this end, efforts to impact depression directly, including some form of cognitive behavioral therapy, emotional and social support, plus a combination of adequate nutrition, exercise, stress control strategies, weight management, and sleep, plus efforts to minimize inflammation and negative beliefs would all appear helpful $[23,44]$. Minimizing the extent of any comorbid condition, plus reducing the risk for cardiovascular disease, insofar as these problems can heighten the risk of depression, plus educating osteoarthritis sufferers' about treatment options can potentially help affected individual's to control their pain, and thereby to heighten or optimize their mental function [34]. Finally, reducing the stigma of depression may be helpful as well [57]. In particular, exercise alone may have a beneficial effect on depression symptoms that is comparable to that of antidepressant treatments [96]. It is also argued that because stress and depression are both associated with the development of later life medical comorbidities as well as the onset and worsening of osteoarthritis, pain, disability, and poor health, careful evaluation to tease out the presence of physical symptoms, versus emotional distress, followed by interventions such as relaxation, may be helpful in reducing osteoarthritis related disability, especially in over-anxious and/or chronically ill patients [44,97-100]. In turn, therapies that foster feelings of efficacy and confidence and engage the mental and social capacities of the arthritis sufferer are expected to positively impact overall well-being, as well as mental health status [91,101]. Educational programs to foster an individual's self-management capacity, may similarly heighten the individual osteoarthritic patient's life quality as outlined in Figure 2, especially those with a family history of psychiatric problems and targeting those with medical conditions, those experiencing prolonged stress, and those with limited social support may be helpful as well [44].

In the interim, applying a comprehensive collaborative care multimodal approach, aimed at alleviating or controlling pain, improving joint function, and minimizing disability that is tailored to the individual and takes into account the complexity of the disease and its symptoms, plus minimizing the onset or extent of any persistent depression, especially as this influences inflammation may permit the osteoarthritis patient to have a higher rather than a lower life quality, and predicts a higher likelihood of a favorable response to intervention and minimization of days of restrictive activity [23,96,102,103]. Moreover, an approach directed at symptom management, which does not have the side effects of pharmaceutical therapies, may be especially valuable for heightening optimal health outcomes, regardless of whether clinical or surgical intervention approaches are employed as outlined by Axford et al. [104] and Lin et al. [105], and Ang et al. [106]. Early intervention may also reduce symptoms of hypertension and heart disease and asthma caused by psychological distress, excess body weight and pain and disability, which in turn can cause depression, high rates of health care utilization and excess analgesic drug use $[24,30,80,96]$. Finally, since depression is a consistent predictor of pain among adults with chronic pain, perceived health and functional ability, activity limitations, disability, and operative outcomes in cases with knee osteoarthritis, there is compelling support for concerted efforts by clinicians to routinely screen adults with joint pain and functional limitations, as well as those definitive osteoarthritis for depression, and to make appropriate referrals $[99,107]$. 


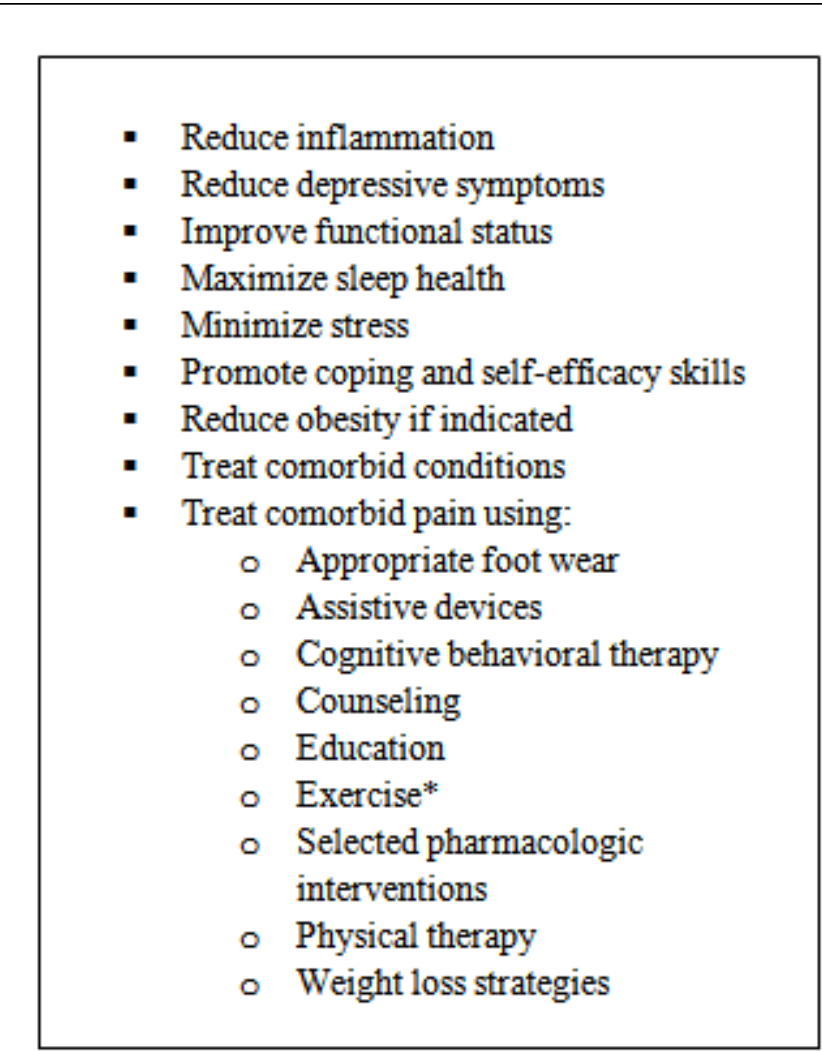

Figure 2. Selected strategies for preventing and treating osteoarthritis and depression

\section{References}

1. Zhang Y, Jordan JM. (2010) Epidemiology of osteoarthritis. Clin Geriatr Med 26: 355-369.

2. Kwok WY, Vliet Vlieland TP, Rosendaal FR, Huizinga TW, Kloppenburg M. (2011) Limitations in daily activities are the major determinant of reduced health-related quality of life in patients with hand osteoarthritis. Ann Rheum Dis 70: 334-336.

3. Murphy L, Helmick CG. (2012) The impact of osteoarthritis in the United States: a population-health perspective: A population-based review of the fourth most common cause of hospitalization in U.S. adults. Orthop Nurs 31: 85-91.

4. Moskowitz RW. (2009) The burden of osteoarthritis: clinical and qualityof-life issues. Am J Manag Care 15: S223-229.

5. Swift A. (2012) Osteoarthritis 1: physiology, risk factors and causes of pain. Nurs Times 108: 12-15.

6. Martel-Pelletier J, Boileau C, Pelletier JP, Roughley PJ. (2008) Cartilage in normal and osteoarthritis conditions. Best Pract Res Clin Rheumatol 22: 351-384.

7. Kubota M, Ishijima M, Kurosawa H, Liu L, Ikeda H, et al. (2010) A longitudinal study of the relationship between the status of bone marrow abnormalities and progression of knee osteoarthritis. J Orthop Sci 15: 641-646.

8. Sinusas K (2012) Osteoarthritis: diagnosis and treatment. Am Fam Physician 85: 49-56.

9. McDonough CM, Jette AM. (2010) The contribution of osteoarthritis to functional limitations and disability. Clin Geriatr Med 26: 387-399.
10. Edwards RR, Calahan C, Mensing G, Smith M, Haythornthwaite JA (2011) Pain, catastrophizing, and depression in the rheumatic diseases. Nat Rev Rheumatol 7: 216-224.

11. Heliovaara M, Makela M, Impivaara O, Knekt P, Aromaa A, et al. (1993) Association of overweight, trauma, and workload with coxarthrosis. A health survey of 7,217 persons. Acta Orthop Scandinav 64: 513-518.

12. Philbin EF, Groff GD, Ries MD, Miller TE. (1995) Cardiovascular fitness and health in patients with end-stage osteoarthritis. Arthritis Rheum 38: 799-805.

13. Knoop J, Steultjens MP, van der Leeden $M$, van der Esch $M$, Thorstensson CA, et al. (2011) Proprioception in knee osteoarthritis: a narrative review. Osteoarthritis Cartilage 19: 381-388.

14. Ratzlaff CR, Steininger G, Doerfling P, Koehoorn M, Cibere J, et al. (2011) Influence of lifetime hip joint force on the risk of self-reported hip osteoarthritis: a community-based cohort study. Osteoarthritis Cartilage 19: 389-398

15. Tepper S, Hochberg MC (1993) Factors associated with hip osteoarthritis: data from the First National Health and Nutrition Examination Survey (NHANES-I). Am J Epidemiol 137: 1081-1088.

16. Dexter P, Brandt K (1994) Distribution and predictors of depressive symptoms in osteoarthritis. J Rheumatol 21:279-286.

17. Power JD, Badley EM, French MR, Wall AJ, Hawker GA (2008) Fatigue in osteoarthritis: a qualitative study. BMC Musculoskelet Disord 9: 63

18. Bischoff-Ferrari HA, Lingard EA, Losina E, Baron JA, Roos EM, et al. (2004) Psychosocial and geriatric correlates of functional status after total hip replacement. Arthritis Rheum 51: 829-835.

19. Caracciolo B, Giaquinto S (2005) Self-perceived distress and selfperceived functional recovery after recent total hip and knee arthroplasty. Arch Gerontol Geriatr 41: 177-181.

20. Okma-Keulen P, Hopman-Rock M (2001) The onset of generalized osteoarthritis in older women: a qualitative approach. Arthritis Rheum 45: $183-190$.

21. Axford J, Butt A, Heron C, Hammond J, Morgan J, et al. (2010) Prevalence of anxiety and depression in osteoarthritis: use of the Hospital Anxiety and Depression Scale as a screening tool. Clin Rheumatol 29: 1277-1283.

22. Somers TJ, Keefe FJ, Godiwala N, Hoyler GH (2009) Psychosocial factors and the pain experience of osteoarthritis patients: new findings and new directions. Curr Opin Rheumatol 21: 501-506.

23. Yohannes AM, Caton S (2010) Management of depression in older people with osteoarthritis: A systematic review. Aging Ment Health 14: 637-651

24. Wu LR, Parkerson GR Jr, Doraiswamy PM (2002) Health perception, pain, and disability as correlates of anxiety and depression symptoms in primary care patients. J Am Board Fam Pract 15: 183-190.

25. Alshami AM (2014) Knee osteoarthritis related pain: a narrative review of diagnosis and treatment. Int J Health Sci (Qassim) 8: 85-104.

26. Margaretten ME, Katz P, Schmajuk G, Yelin E (2013) Missed opportunities for depression screening in patients with arthritis in the United States. J Gen Intern Med 28: 1637-1642.

27. Bijlsma JW, Berenbaum F, Lafeber FP (2011) Osteoarthritis: an update with relevance for clinical practice. Lancet 377: 2115-2126.

28. Lawrence RC, Hochberg MC, Kelsey JL, McDuffie FC, Medsger TA Jr, et al. (1989) Estimates of the prevalence of selected arthritic and musculoskeletal diseases in the United States. J Rheumatol 16: 427-441.

29. Buckwalter JA, Stanish, WD, Rosier RN, Schenck RC, Douglas DA et al. (2001) The increasing need for nonoperative treatment of patients with osteoarthritis. Clin Orthop Rel Res 385: 36-45.

30. Montin L, Leino-Kilpi H, Katajisto J, Lepistö J, Kettunen J, et al. (2007) Anxiety and health-related quality of life of patients undergoing total hip arthroplasty for osteoarthritis. Chronic Illn 3: 219-227.

31. Macfarlane D (1992) Osteoarthritis. Practitioner 236: 1061-1065.

32. Ringdahl E, Pandit S (2011) Treatment of knee osteoarthritis. Am Fam Physician 83: 1287-1292. 
33. Schnitzer TJ (1993) Osteoarthritis treatment update. Minimizing pain while limiting patient risk. Postgrad Med 93: 89-92, 95.

34. Felson DT (1993) The course of osteoarthritis and factors that affect it. Rheum Dis Clin North Am 19: 607-615.

35. Griffin MR, Brandt KD, Liang MH, Pincus T, Ray WA (1995) Practical management of osteoarthritis. Integration of pharmacologic and nonpharmacologic measures. Arch Fam Med 4: 1049-1055.

36. Monson RR, Hall AP (1976) Mortality among arthritics. J Chronic Dis 29: 459-467.

37. Perruccio AV, Davis AM, Hogg-Johnson S, Badley EM (2011) Importance of self-rated health and mental well-being in predicting health outcomes following total joint replacement surgery for osteoarthritis. Arthritis Care Res (Hoboken) 63: 973-981.

38. Marks R, Allegrante JP (2002) Effectiveness of psychoeducational interventions in osteoarthritis. Crit Rev Phys Rehabil Med 14: 173-195.

39. Alexopoulos GS (2005) Depression in the elderly. Lancet 365: 1961-1970.

40. López-López A, Montorio I, Izal M, Velasco L (2008) The role of psychological variables in explaining depression in older people with chronic pain. Aging Ment Health 12: 735-745.

41. Pilling S, Anderson I, Goldberg D, Meader N, Taylor C; Two Guideline Development Groups. (2009) Depression in adults, including those with a chronic physical health problem: summary of NICE guidance. BMJ 339 b4108. doi:10.1136/bmj.b4108.

42. Andrews LW. (2010) Encyclopedia of Depression, Volume 2. California, Greenwood. pp 285-289.

43. Nestler EJ, Barrot M, DiLeone RJ, Eisch AJ, Gold SJ, et al. (2002) Neurobiology of depression. Neuron 34: 13-25.

44. Rosemann T, Laux G, Szecsenyi J (2007) Osteoarthritis: quality of life, comorbidities, medication and health service utilization assessed in a large sample of primary care patients. J Orthop Surg Res 2: 12.

45. DziechciaÅ M, Balicka-Adamik L, Filip R3 (2013) The problem of pain in old age. Ann Agric Environ Med Spec no.

46. Dimitroulas T, Duarte RV, Behura A, Kitas GD, Raphael JH (2014) Neuropathic pain in osteoarthritis: A review of pathophysiological mechanisms and implications for treatment. Semin Arthritis Rheum

47. Felson DT, Chaisson CE, Hill CL, Totterman SM, Gale ME, et al. (2001) The association of bone marrow lesions with pain in knee osteoarthritis. Ann Intern Med 134: 541-549.

48. Salaffi F, Cavalieri F, Nolli M, Ferraccioli G (1991) Analysis of disability in knee osteoarthritis. Relationship with age and psychological variables but not with radiographic score. J Rheumatol 18: 1581-1586.

49. Dekker J, Boot B, van der Woude LH, Bijlsma JW (1992) Pain and disability in osteoarthritis: a review of biobehavioral mechanisms. J Behav Med 15: 189-214.

50. Dekker J, Tola P, Aufdemkampe G, Winckers M (1993) Negative affect, pain and disability in osteoarthritis patients: the mediating role of muscle weakness. Behav Res Ther 31: 203-206.

51. Keefe FJ, Caldwell DS, Williams DA, Gil KM, Mitchell D et al. (1990) Pain coping skills in the training in the management of osteoarthritic knee pain: a comparative study. Behav Ther 21: 49-62.

52. Johnson VL, Hunter DJ (2014) The epidemiology of osteoarthritis. Best Pract Res Clin Rheumatol 28: 5-15.

53. Howell SI (1994) A theoretical model of caring for women with chronic non-malignant pain. Qual Hlth Res 4: 94-122.

54. Wenham CY, Conaghan PG (2010) Optimising pain control in osteoarthritis. Practitioner 254: 23-26, 2-3.

55. Wells KB, Stewart A, Hays RD, Burnam MA, Rogers W, et al. (1989) The functioning and well-being of depressed patients. Results from the Medical Outcomes Study. JAMA 262: 914-919.

56. Areán PA, Mackin S, Vargas-Dwyer E, Raue P, Sirey JA, et al. (2010) Treating depression in disabled, low-income elderly: a conceptual model and recommendations for care. Int J Geriatr Psychiatry 25: 765-769.

57. Qiu WQ, Dean M, Liu T, George L, Gann M, et al. (2010) Physical and mental health of homebound older adults: an overlooked population. J Am Geriatr Soc 58: 2423-2428.
58. Colón-Emeric CS, Whitson HE, Pavon J, Hoenig H (2013) Functional decline in older adults. Am Fam Physician 88: 388-394.

59. Chiou AF, Lin HY, Huang HY (2009) Disability and pain management methods of Taiwanese arthritic older patients. J Clin Nurs 18: 2206-2216.

60. Duivenvoorden T, Vissers MM, Verhaar JA, Busschbach JJ, Gosens T, et al. (2013) Anxiety and depressive symptoms before and after total hip and knee arthroplasty: a prospective multicentre study. Osteoarthritis Cartilage 21: 1834-1840.

61. Grundy A, Cotterchio M2, Kirsh VA2, Kreiger N3 (2014) Associations between anxiety, depression, antidepressant medication, obesity and weight gain among Canadian women. PLoS One 9: e99780.

62. Riddle DL, Kong X, Fitzgerald GK (2011) Psychological health impact on 2 -year changes in pain and function in persons with knee pain: data from the Osteoarthritis Initiative. Osteoarthritis Cartilage 19: 1095-1101.

63. Dekker J, van Dijk GM, Veenhof C (2009) Risk factors for functional decline in osteoarthritis of the hip or knee. Curr Opin Rheumatol 21: 520-524

64. Allen KD, Renner JB, Devellis B, Helmick CG, Jordan JM (2008) Osteoarthritis and sleep: the Johnston County Osteoarthritis Project. J Rheumatol 35: 1102-1107.

65. Broderick JE, Junghaenel DU, Schneider S, Bruckenthal P, Keefe FJ (2011) Treatment expectation for pain coping skills training: relationship to osteoarthritis patients' baseline psychosocial characteristics. Clin J Pain 27: 315-322.

66. Hill S, Dziedzic KS, Ong BN (2010) The functional and psychological impact of hand osteoarthritis. Chronic Illn 6: 101-110.

67. Aflaki E, Parang A, Ghanizadeh A. (2010) Depression in patients with hand and knee osteoarthritis. Int J Rheum Dis 113(Suppl 1): 163.

68. Abdel-Nasser AM, Abd El-Azim S, Taal E, El-Badawy SA, Rasker JJ, et al. (1998) Depression and depressive symptoms in rheumatoid arthritis patients: an analysis of their occurrence and determinants. $\mathrm{Br} \mathrm{J}$ Rheumatol 37: 391-397.

69. Stebbings S, Herbison P, Doyle TC, Treharne GJ, Highton J (2010) A comparison of fatigue correlates in rheumatoid arthritis and osteoarthritis: disparity in associations with disability, anxiety and sleep disturbance. Rheumatology (Oxford) 49: 361-367.

70. Lunghi ME, Miller PM, McQuillan WM (1978) Psycho-social factors in osteoarthritis of the hip. J Psychosom Res 22: 57-63.

71. Howard KJ, Ellis HB, Khaleel MA, Gatchel RJ, Bucholz R (2011) Psychosocial profiles of indigent patients with severe osteoarthritis requiring arthroplasty. J Arthroplasty 26: 244-249.

72. Lavernia CJ, Alcerro JC, Brooks LG, Rossi MD (2012) Mental health and outcomes in primary total joint arthroplasty. J Arthroplasty 27: 1276-1282.

73. Gore M, Tai KS, Sadosky A, Leslie D, Stacey BR (2011) Clinical comorbidities, treatment patterns, and direct medical costs of patients with osteoarthritis in usual care: a retrospective claims database analysis. J Med Econ 14: 497-507.

74. Sullivan M, Tanzer M, Reardon G, Amirault D, Dunbar M, et al. (2011) The role of presurgical expectancies in predicting pain and function one year following total knee arthroplasty. Pain 152: 2287-2293.

75. van Baar ME, Dekker J, Lemmens JA, Oostendorp RA, Bijlsma JW (1998) Pain and disability in patients with osteoarthritis of hip or knee: the relationship with articular, kinesiological, and psychological characteristics. J Rheumatol 25: 125-133.

76. Summers MN, Haley WE, Reveille JD, Alarcón GS (1988) Radiographic assessment and psychologic variables as predictors of pain and functional impairment in osteoarthritis of the knee or hip. Arthritis Rheum 31: 204-209.

77. Leite AA, Costa AJ, Lima Bde A, Padilha AV, Albuquerque EC, et al (2011) Comorbidities in patients with osteoarthritis: frequency and impact on pain and physical function. Rev Bras Reumatol 51: 118-123.

78. Rosemann T, Backenstrass M, Joest K, Rosemann A, Szecsenyi J, et al. (2007) Predictors of depression in a sample of 1,021 primary care patients with osteoarthritis. Arthritis Rheum 57: 415-422. 
79. Possley D, Budiman-Mak E, O'Connell S, Jelinek C, Collins EG (2009) Relationship between depression and functional measures in overweight and obese persons with osteoarthritis of the knee. J Rehabil Res Dev 46: 1091-1098.

80. Chrischilles EA, Lemke JH, Wallace RB, Drube GA (1990) Prevalence and characteristics of multiple analgesic drug use in an elderly study group. J Am Geriatr Soc 38: 979-984.

81. McCurry SM, Von Korff M, Vitiello MV, Saunders K, Balderson BH, et al. (2011) Frequency of comorbid insomnia, pain, and depression in older adults with osteoarthritis: predictors of enrollment in a randomized treatment trial. J Psychosom Res 71: 296-299.

82. Rosemann T, Gensichen J, Sauer N, Laux G, Szecsenyi J (2007) The impact of concomitant depression on quality of life and health service utilisation in patients with osteoarthritis. Rheumatol Int 27: 859-863.

83. Vali FM, Walkup J (1998) Combined medical and psychological symptoms: impact on disability and health care utilization of patients with arthritis. Med Care 36: 1073-1084.

84. Sale JE, Gignac M, Hawker G (2008) The relationship between disease symptoms, life events, coping and treatment, and depression among older adults with osteoarthritis. J Rheumatol 35: 335-342.

85. McBeth J, Lacey RJ, Wilkie R (2014) Predictors of new-onset widespread pain in older adults: results from a population-based prospective cohort study in the UK. Arthritis Rheumatol 66: 757-767.

86. Sinikallio SH, Helminen EE, Valjakka AL, Väisänen-Rouvali RH, Arokoski JP. (2014) Multiple psychological factors are associated with poorer functioning in a sample of community-dwelling knee osteoarthritis patients. J Clin Rheumatol 2014 Jul 16.

87. Sofat N, Smee C, Hermansson M, Howard M, Baker EH, et al. (2013). Functional MRI demonstrates pain perception in hand osteoarthritis has features of central pain processing. J Biomed Graph Comput 3(4). doi: $10.5430 /$ jbgc.v3n $4 \mathrm{p} 20$

88. Croft P (1996) The epidemiology of pain: the more you have, the more you get. Ann Rheum Dis 55: 859-860.

89. Daltroy LH (1992) Arthritis patient education. Bull Rheum Dis 41: 2-4.

90. Wilcox S, Brenes GA, Levine D, Sevick MA, Shumaker SA, et al. (2000) Factors related to sleep disturbance in older adults experiencing knee pain or knee pain with radiographic evidence of knee osteoarthritis. J Am Geriatr Soc 48: 1241-1251.

91. Keefe FJ, Caldwell DS, Queen KT, Gil KM, Martinez S, et al. (1987) Pain coping strategies in osteoarthritis patients. J Consult Clin Psychol 55: 208-212.

92. Axford JS, Ross F, Triggs E, Victor C. (2000) Osteoarthritis of the knee causes appreciable disability in females associated with depression and inability to cope. Arthritis Rheum 43: S927.

93. Zautra AJ, Smith BW (2001) Depression and reactivity to stress in older women with rheumatoid arthritis and osteoarthritis. Psychosom Med 63: 687-696.
94. Sakalauskien AG, Jauniaikien AD (2010) Osteoarthritis: etiology, epidemiology, impact on the individual and society and the main principles of management. Medicina (Kaunas) 46: 790-797.

95. Marks R (2007) Physical and psychological correlates of disability among a cohort of individuals with knee osteoarthritis. Can J Aging 26: 367-377.

96. Dinas PC, Koutedakis Y, Flouris AD (2011) Effects of exercise and physical activity on depression. Ir J Med Sci 180: 319-325.

97. Oslin DW, Datto CJ, Kallan MJ, Katz IR, Edell WS, et al. (2002) Association between medical comorbidity and treatment outcomes in late-life depression. J Am Geriatr Soc 50: 823-828.

98. Grossniklaus DA, Gary RA, Higgins MK, Dunbar SB (2010) Biobehavioral and psychological differences between overweight adults with and without waist circumference risk. Res Nurs Health 33: 539-551.

99. Parmelee PA, Harralson TL, McPherron JA, Schumacher HR (2013) The structure of affective symptomatology in older adults with osteoarthritis. Int J Geriatr Psychiatry 28: 393-401.

100. Baird CL, Murawski MM, Wu J (2010) Efficacy of guided imagery with relaxation for osteoarthritis symptoms and medication intake. Pain Manag Nurs 11: 56-65.

101. Unützer J, Hantke M, Powers D, Higa L, Lin E, et al. (2008) Care management for depression and osteoarthritis pain in older primary care patients: a pilot study. Int J Geriatr Psychiatry 23: 1166-1171.

102. Hamer M, Molloy GJ, de Oliveira C, Demakakos P. (2009) Persistent depressive symptomatology and inflammation: to what extent do health behaviours and weight control mediate this relationship? Brain Behav Immun 23: 413-418.

103. Weiner DK, Moore CG, Morone NE, Lee ES, Kent Kwoh C (2013) Efficacy of periosteal stimulation for chronic pain associated with advanced knee osteoarthritis: a randomized, controlled clinical trial. Clin Ther 35: 1703-1720.

104. Axford J, Heron C, Ross F, Victor CR (2008) Management of knee osteoarthritis in primary care: pain and depression are the major obstacles. J Psychosom Res 64: 461-467.

105. Lin EH, Katon W, Von Korff M, Tang L, Williams JW Jr, et al. (2003) Effect of improving depression care on pain and functional outcomes among older adults with arthritis: a randomized controlled trial. JAMA 290: 2428-2429.

106. Ang DC, Bair MJ, Damush TM, Wu J, Tu W, et al. (2010) Predictors of pain outcomes in patients with chronic musculoskeletal pain co-morbid with depression: results from a randomized controlled trial. Pain Med 11: 482-491.

107. Peters TJ, Sanders C, Dieppe P, Donovan J (2005) Factors associated with change in pain and disability over time: a community-based prospective observational study of hip and knee osteoarthritis. Br J Gen Pract 55: 205-211. 